\title{
A INFLUÊNCIA DO AMBIENTE ORGANIZACIONAL NO DESENVOLVIMENTO DE UM PROGRAMA DE COMPETÊNCIA EM INFORMAÇÃO: O CASO DE UMA BIBLIOTECA PÚBLICA
}

\author{
THE INFLUENCE OF THE ORGANIZATIONAL \\ ENVIRONMENT IN THE DEVELOPMENT OF AN \\ INFORMATION LITERACY PROGRAM: THE CASE OF A \\ PUBLIC LIBRARY
}

\author{
Tânia Regina de Britoa \\ Regina Celia Baptista Belluzzob \\ Marta Lígia Pomim Valentim
}

\begin{abstract}
RESUMO
Introdução: Apresenta a biblioteca pública como um espaço de mediação, cujo ambiente organizacional tem influência na construção do conhecimento do usuário, e por conseguinte, no desenvolvimento de um programa de competência em informação. Objetivo: Refletir sobre a influência do ambiente organizacional para o desenvolvimento de um programa de competência em informação. Metodologia: Trata-se de um estudo de natureza qualitativa, a partir de uma revisão de literatura realizada no Portal de Periódicos da CAPES envolvendo as temáticas 'informação', 'conhecimento', 'sociologia da informação e do conhecimento', 'competência em informação', 'biblioteca pública' e 'biblioteca como organização'. É também uma pesquisa de campo, com o uso da técnica de entrevista semiestruturada. Resultados: A entrevista semiestruturada realizada com o responsável da Biblioteca Pública Estadual Dr. Isaías Paim, na Cidade de Campo Grande, Estado do Mato Grosso do Sul, evidencia que as atividades desenvolvidas neste espaço apresentam elementos relacionados com dimensões da competência em informação, contudo não apresentam um programa ou projeto voltado para este fim. Conclusões: Compreende-se que o ambiente organizacional de bibliotecas públicas é influenciado por condições internas e externas que interferem nas condições de acesso

\footnotetext{
a Doutoranda em Ciência da Informação pela Universidade Estadual Paulista Júlio de Mesquita Filho (UNESP). Bibliotecária-Documentalista da Universidade Federal de Mato Grosso do Sul (UFMS). E-mail: taniacgms@gmail.com. Programas de Pós-Graduação em Ciência da Informação da Universidade Estadual Paulista Júlio de Mesquita Filho (UNESP/Marília) e Mídia e Tecnologia (Unesp/Bauru). E-mail: rbelluzzo@gmail.com.

c Doutora em Ciências da Comunicação pela Escola de Comunicação e Artes (ECA), da Universidade de São Paulo (USP). Docente do Programas de Pós-Graduação em Ciência da Informação da Universidade Estadual Paulista (UNESP). E-mail: valentim@valentim.pro.br.
}

b Doutora em Ciências da Comunicação pela Universidade de São Paulo. Docente dos
\end{abstract}


à informação, sobretudo de pessoas em condições de vulnerabilidade social, como as pessoas em situação de rua que frequentam essas organizações.

Descritores: Biblioteca Pública. Ambiente Organizacional. Competência em Informação. Vulnerabilidade Social.

\section{INTRODUÇÃO}

A biblioteca como um espaço de mediação entre a informação e as pessoas que a ela recorrem pode ser entendida como um ambiente organizacional, cujo enfoque se refere ao acesso à cultura, à leitura, ao atendimento a distintas necessidades informacionais, ao entretenimento, à socialização, à aprendizagem contínua, entre outros. Na biblioteca pública, em que o público é heterogêneo, evidencia-se significativa influência no ambiente organizacional, recebida tanto do ambiente interno quanto do ambiente externo.

Segundo Cavalcante e Valentim (2010), tanto o ambiente interno ou microambiente, quanto o ambiente externo ou macroambiente de uma organização interagem entre si, alicerçando os ambientes informacionais. A estrutura de uma organização [infraestrutura, pessoas e tecnologias] se constitui em elemento essencial para o desenvolvimento de qualquer processo organizacional. Organizações que possuem uma função social, como as bibliotecas públicas, precisam refletir sobre a influência dessa estrutura no ambiente organizacional em prol de atividades que desenvolvam o senso crítico nas pessoas no que concerne a suas relações com o universo informacional.

Quando se afirma que os ambientes - interno e externo - de uma organização interagem, pauta-se na afirmação de Almeida e Freire (2018) ao destacarem que bibliotecas são aprendentes por meio de seus profissionais, uma vez que usam o conhecimento que adquiriram para criar e oferecer serviços e produtos inovadores aos seus usuários. Tais serviços e produtos devem visar à competência em informação (Coinfo), entendida como:

[...] o conjunto de habilidades integradas que abrangem a descoberta reflexiva da informação, a compreensão de como a informação é produzida e valorizada e o uso da informação na criação de novos conhecimentos e na participação ética em comunidades de aprendizagem. (ACRL, 2015, p. 12) 
De acordo com Belluzzo (2018), o processo de competência em informação está fundamentado no pensamento crítico e na avaliação, envolvendo ainda questões como a fluidez com a Tecnologia da Informação e da Comunicação (TIC).

Ainda sobre as bibliotecas com o perfil de aprendentes, observa-se que o desempenho organizacional é influenciado pela inovação gerencial, por sua vez, impulsionada pela gestão dos recursos de informação associada à cultura da aprendizagem organizacional. (ALMEIDA; FREIRE, 2018, p. 3793).

Pensar o aprendizado e, por conseguinte o conhecimento, na perspectiva de quem em princípio tem a missão de oferecer e daquele que se dispõe a receber ou está à procura do que receber, conduz a uma reflexão a partir de Morin (2002) quando afirma que aprender envolve o 'como', isto é, o modo com que o sujeito lida com informação para que o saber seja adquirido. Esse saber pode não estar relacionado apenas à apropriação de informações, mas de descobertas e vivências, estabelecimento de relações entre coisas, seres, acontecimentos, ou mesmo a ausência dessas relações. Para este autor, aprender envolve uma dialógica auto-eco-organizadora, sendo assim a aprendizagem é concebida pela dialógica inato/adquirido, mas também inato/adquirido/construído.

Transportando as ideias do autor supracitado, de um nível de plasticidade bioquímica do aparelho cerebral, necessitando este de estímulos do meio/contexto para o seu desenvolvimento e limitando-nos, neste momento, a considerar a biblioteca como uma organização, e parte de uma organização maior, entende-se ser relevante a compreensão das estruturas da sua 'eco organização'. Em termos práticos citamos como exemplo, a compreensão dos servidores da biblioteca sobre a estrutura organizacional, como se vêm, como se posicionam, perante a organização da qual fazem parte, bem como diante das pessoas que a frequentam ou possam vir a frequentá-la, buscando cumprir a sua missão.

Neste estudo, o universo de reflexão envolve a Biblioteca Pública Estadual Dr. Isaías Paim, localizada em Campo Grande, Mato Grosso do Sul, sendo objetivo deste artigo refletir sobre a influência do ambiente organizacional 
para o desenvolvimento de um programa de competência em informação.

\section{MATERIAIS E MÉTODOS}

O estudo se caracteriza como sendo de natureza qualitativa, tratando-se de uma revisão de literatura apoiada nos princípios de Marconi e Lakatos (2016), e decorrente das consultas em artigos de periódicos, livros, trabalhos em eventos, teses e dissertações com abordagens sobre informação, conhecimento, sociologia da informação e do conhecimento. Para tanto, foram realizadas buscas no Portal de Periódicos da Coordenação de Aperfeiçoamento de Pessoal de Nível Superior (CAPES), bem como em catálogos e bases de dados de instituições de ensino superior.

Para a realização da estratégia de busca utilizou-se as seguintes palavras-chave em português: 'competência em informação', 'biblioteca pública' e 'biblioteca como organização'. Posteriormente à leitura e análise dos materiais recuperados e pertinentes, buscou-se apresentar uma reflexão sobre a influência do ambiente organizacional de uma biblioteca pública, em prol de atividades que busquem o senso crítico nas pessoas, no que se referem as suas relações com o universo informacional, abrindo possibilidades para o desenvolvimento de um programa de competência em informação.

Além disso, a pesquisa também é do tipo descritivo e exploratório, pois se trata de uma pesquisa de campo que fez uso da técnica da entrevista para a coleta de dados com a bibliotecária responsável pela Biblioteca Pública Estadual Dr. Isaías Paim, Cidade de Campo Grande, Estado do Mato Grosso do Sul, tendo a mesma, anuído participar da pesquisa e assinado um "Termo de Consentimento Livre e Esclarecido" como protocolo de garantia da ética. A modalidade de entrevista foi a on-line assincrônica "[...] em que você envia suas perguntas aos participantes, e eles encaminham suas respostas de volta mais tarde: neste caso vocês não precisam necessariamente estar conectados ao mesmo tempo." (FLICK, 2013, p. 168).

Oito questões abertas iniciais foram encaminhadas e respondidas por email, direcionadas à coordenadora e bibliotecária responsável pela Biblioteca 
supracitada, sujeito participante da pesquisa. Para uma melhor compreensão, mais duas questões abertas foram enviadas à mesma, a fim de compreender acerca da formação e atribuições dos funcionários das bibliotecas junto aos usuários, assim como em relação aos projetos desenvolvidos pela biblioteca, visando estabelecer conexões com as dimensões da competência em informação de Vitorino e Piantola (2011).

Manzini (2004, p. 2) explica que a entrevista semiestruturada "[...] pode fazer emergir informações de forma mais livre e as respostas não estão condicionadas a uma padronização de alternativas".

Os dados obtidos foram analisados sob a concepção do referencial teórico da pesquisa em questão.

\section{A BIBLIOTECA PÚBLICA COMO ORGANIZAÇÃO DO CONHECIMENTO}

Ilharco (2003) considera que a estrutura e as dimensões organizacionais que permeiam a vida em sociedade, estabelecem determinados significados referentes ao que se denomina Sociedade da Informação. Segundo este autor, a organização é fundadora das sociedades contemporâneas, podendo ser "[...] entendida e estudada como um fenômeno de informação e comunicação" (ILHARCO, 2003, p. 93), e que tem sofrido grande impacto das tecnologias de informação e comunicação nas últimas décadas.

As bibliotecas, independente da tipologia a qual pertencem, em geral são organizações que fazem parte de uma organização maior e possuem conhecimento organizado na sua essência, embora possam desenvolver muitas outras atividades que as diferenciam de uma para outra. Todas elas, no entanto, estão relacionadas ao acesso à informação e ao conhecimento, levando-se em conta a afirmação de Morin (2002, p. 58) de que "[...] a vida só pode autoorganizar-se com conhecimento. A vida só é viável e passível de ser vivida com o conhecimento", reflete-se assim que, além do conhecimento vivo (máquina viva) ou do conhecimento artificial (máquina artificial), o conhecimento organizacional envolve em uma visão macro, os dois conhecimentos.

No contexto deste estudo, a biblioteca pública precisa ter clareza sobre o 
modo como se vê enquanto organização, pois este reflete no ambiente organizacional e, por conseguinte, nas suas relações com seus usuários. As normas fazem parte dessas relações, sejam elas técnicas ou referentes a procedimentos de gestão, sendo que no caso específico de uma biblioteca pública são entendidas conforme destaca Mattelart (2006, p. 24): "A norma é aquilo que assegura a integração das partes ao todo. Quer elas sejam de caráter técnico ou comportamental, são as normas e os procedimentos que determinam os critérios de eficiência da organização". Desse modo, os sistemas de classificação usados em uma biblioteca pública, por exemplo, refletem na organização e na disponibilização do acervo às pessoas que a frequentam. $O$ regulamento que rege o seu funcionamento também é uma espécie de normatização que estabelece a quem se destina, os procedimentos para empréstimo e devolução, entre outros. As atividades atribuídas a cada um dos servidores de uma biblioteca, em função de seus cargos é similarmente uma espécie de norma que igualmente interfere em toda a organização (biblioteca), sendo ela mesma influenciada pela organização maior da qual faz parte.

No ano 2019 os estudos internacionais liderados pela Seção de Bibliotecas Públicas da Federação Internacional de Associações e Instituições Bibliotecárias (IFLA) completaram 46 anos, e o "Manifesto da IFLA/UNESCO sobre bibliotecas públicas" (IFLA, 1994) completou 25 anos de sua publicação. Esses documentos internacionais, bem como outros em defesa da biblioteca pública e da prestação de serviços bibliotecários de qualidade à população, são reconhecidos, difundidos e avançam na atualização e adequação às mudanças tecnológicas e de comportamento da sociedade em geral, reforçando o papel social dessas organizações.

Desse modo, um dos aspectos mais relevantes dentro da organização biblioteca é levar em conta o que pensam, querem e necessitam seus usuários ou frequentadores. Embora seus procedimentos técnicos sejam imprescindíveis para o acesso, compartilhamento e socialização do conhecimento, apoia-se na afirmação de Carvalho (2004) sobre bibliotecas universitárias, mas que se entende, aplicável a qualquer tipologia de biblioteca, inclusive as públicas:

Precisamos abandonar a percepção e, mais do que a percepção, 
a prática de centrar a biblioteca em sua própria organização, de oferecer serviços e produtos já preparados e testados na perspectiva somente do bibliotecário, como algo imutável ou passível apenas de pequenas adaptações. Se pretendem atender às expectativas, às necessidades e aos desejos de seus usuários, ou seja de reconhecê-los como elemento norteador de suas atividades [...] precisam começar por mapear as características e demandas desses usuários, aceitando o ponto de vista deles como o que prevalece na definição da política de serviços e produtos" (CARVALHO, 2004, p. 165).

Se na história, de acordo com Burke (2003), o acesso às bibliotecas públicas era em parte influenciado pela sua localização geográfica, estando algumas pessoas ou regiões em desvantagem a outras, observa-se que a Sociologia, ainda hoje é imprescindível a esta organização do conhecimento, conforme afirma este autor: "Além da geografia, também a sociologia das bibliotecas é relevante para a história da aquisição do conhecimento. $O$ acesso às primeiras bibliotecas modernas dependia das atitudes do bibliotecário e de sua equipe" (BURKE, 2003, p. 160). Entende-se que tal característica ou evidência, sempre será atual e de conveniente reflexão. Um ambiente que leva em conta as necessidades de seus usuários concorre para que tal acesso seja facilitado.

\section{A RELAÇÃO DA BIBLIOTECA PÚBLICA COM O COMPORTAMENTO INFORMACIONAL DOS USUÁRIOS: ALGUMAS CONSIDERAÇÕES}

A máxima de que a razão de ser de qualquer biblioteca são os seus usuários deve subsidiar as decisões dessas organizações. Acredita-se que em uma biblioteca pública o diálogo estabelecido com o seu público, influencia sobremaneira o modo relacional entre os agentes que representam e trabalham nas bibliotecas, e a quem ela se destina. Sob esta perspectiva, o comportamento informacional do público, usuário ou interagente pode ser mais bem compreendido.

Em análise acerca da formação e atuação do bibliotecário, Valentim (2019) afirma que este profissional necessita levar em consideração o próprio desenvolvimento de competências e habilidades que colaborem na formulação 
de políticas públicas de acesso à informação. Tal reflexão está ancorada em documentos da IFLA que indicam as tendências e as perspectivas dos profissionais que atuam em bibliotecas, em especial os bibliotecários, destacando a importância que o protagonismo em incentivar práticas geradoras de conteúdos e serviços de informação pode ter, produzindo o empoderamento de vozes e grupos que surgem em sociedades hiperconectadas.

Assim, os bibliotecários podem contribuir no processo de ensinoaprendizagem para o letramento informacional dos usuários, colaborando para o desenvolvimento cognitivo do aprendiz e melhorias no seu comportamento informacional, como a busca e uso da informação, por meio de competências informacionais (GASQUE, 2017).

Outrossim, são muitos os fatores influenciadores do sucesso ou fracasso no desempenho do papel de uma biblioteca pública perante a sociedade/comunidade da qual faz parte. Fonseca (2007) evidencia que, no Brasil, a burocracia instalada em instituições mantidas por governos estaduais ou municipais é uma delas, o que se traduz, não raras vezes, em "bolorentas repartições". O mesmo autor, entretanto, também traz à lembrança a ideia primeira das bibliotecas públicas, mencionando um pouco dessa história:

Como recorda Jesse $\mathrm{H}$. Shera, em sua já citada Introduction to library science, a ideia da verdadeira biblioteca pública surgiu no começo do século XIX, como o movimento liderado por Horace Mann e Henry Barnard, em favor da educação para todos os segmentos da sociedade. Já havia as bibliotecas escolares, mas aqueles notáveis educadores queriam muito mais. Para eles o programa nacional de educação somente se completaria com o estabelecimento de bibliotecas para todo o povo, enfaticamente consideradas 'a glória de nossas escolas públicas' (FONSECA, 2007, p. 55).

Assim, as estruturas de uma organização como a biblioteca pública, sejam elas físicas, referente às pessoas, tecnológicas etc., podem aproximar ou afastar os que podem ter algum interesse nesses espaços informacionais. Recorrendo a Fonseca (2007), identifica-se que uma das funções da biblioteca pública está relacionada à competência em informação, uma vez que sua importância também reside "[...] na alfabetização de adultos e na educação permanente", a última, um dos pressupostos da competência em informação. A IFLA (1994, p. 
2) menciona inclusive como uma de suas missões: "[...] apoiar a educação individual e a autoformação, assim como a educação formal a todos os níveis". No entanto, ressalta-se que tal autoformação está condicionada, em partes, ao processo mediador da biblioteca pública, fator que contribui para a construção de conhecimento do usuário, tal assertiva estando em concordância com Almeida Júnior (2015, p. 11) quando afirma: "Somos dependentes dos outros na construção de nosso conhecimento [...] nosso conhecimento se constrói mediado e, da mesma forma, somos mediadores na construção do conhecimento dos outros".

Face ao exposto, faz-se uma reflexão sobre o importante papel mediador da biblioteca, o que exige que seus profissionais desenvolvam a competência em informação, para que possam colocar em prática as atividades-fim da organização (biblioteca), sejam elas referentes à informação (registros de informação) ou ao conhecimento (ligadas aos conceitos e ideias) (SANTOS NETO; ALMEIDA JÚNIOR, 2015) e, assim, poder contribuir com a comunidade e seus usuários, sendo os dirigentes responsáveis e autoridades competentes "[...] conscientes da importância que as bibliotecas públicas podem exercer, por exemplo, na alfabetização de adultos e na educação permanente" (FONSECA, 2007).

Outrossim, os gestores de bibliotecas públicas precisam estar atentos, para que o princípio social de igualdade do acesso à informação esteja presente em suas ações mediadoras. Para tanto, torna-se imprescindível observar o caráter e fragilidades humanas, sobretudo sob a perspectiva da vulnerabilidade social. Ressalta-se, conforme Busso (2001), que todas as pessoas estão, para mais ou para menos, sujeitas à vulnerabilidade. E elas são múltiplas podendo ser cumulativas, tais como as vulnerabilidades sociais, econômicas, culturais, pessoais, etárias, resultantes de exclusão social (ARAGÃO, 2011), entre outras. Um exemplo observado a partir de nossos estudos iniciais, em que se identifica por meio da literatura científica, acerca das pessoas que vivem em uma situação de rua, pois também vivenciam um "[...] universo de vida hostil, ameaçador e violento", enfrentam problemas com álcool e drogas, estão desempregados ou atuam em subempregos, sofrendo preconceitos diversos, problemas 
psicológicos (JUSTO, 2011), citando algumas das vulnerabilidades a que estão expostas as pessoas nesta condição.

\section{5 (POR ONDE ANDA) A COMPETÊNCIA EM INFORMAÇÃO NO AMBIENTE ORGANIZACIONAL DA BIBLIOTECA PÚBLICA ESTADUAL DR. ISAÍAS PAIM? COM A PALAVRA, A BIBLIOTECA}

A competência em informação entendida como um direito humano básico que promove a inclusão social (GARNER, 2006) possui pré-requisitos que podem modificar a relação que as pessoas têm com o acesso à informação e com a informação em si, promovendo uma melhor compreensão da abrangência do universo informacional. Pode ser entendida como um processo que se constitui de "[...] atividades que objetivam desenvolver o senso crítico das pessoas em relação ao uso da informação" (BELLUZZO; SANTOS; ALMEIDA JÚNIOR, 2014, p. 67).

O Manifesto de Florianópolis (2013), um dos marcos históricos em nosso contexto, entende a competência em informação como um direito fundamental das pessoas, e defende que deveria ser um dos programas básicos de toda biblioteca pública, levando-se em conta a dimensão social que ambas (biblioteca pública e competência em informação) abrangem.

Em um ambiente organizacional, a relevância da competência em informação pode ser mencionada, por exemplo, no ambiente interno: relacionada à tomada de decisão ou formação continuada dos profissionais; e no ambiente externo: relacionada à obtenção de vantagens que possam proporcionar benefícios aos usuários, como a aprendizagem ao longo da vida, potencializadores do acesso, filtragem, avaliação da informação como essenciais, sendo diferenciais para a vida profissional, social e pessoal do sujeito.

Em perspectiva contrária, o excesso ou a falta de acesso ao universo informacional, resultam em alguma espécie de prejuízo às pessoas. Vitorino tem desenvolvido pesquisas, a fim de identificar e descrever o que denomina de vulnerabilidade em informação: 
[...] a vulnerabilidade em informação é um estado de susceptibilidade a danos causados às pessoas por excesso de exposição à informação ou falta de acesso à informação e a tensões associadas a esse fenômeno na sociedade, devido à ausência de resiliência no que concerne ao desenvolvimento das dimensões técnica, estética, ética e política da competência em informação. (VITORINO, 2018, p. 82).

Em termos do desenvolvimento da competência em informação, destacam-se quatro dimensões: 1. dimensão técnica (saber fazer); 2. dimensão estética (sensibilidade, inovação, transformação); 3. dimensão ética (virtudes, atitudes para o bem comum); 4. dimensão política (mediação e interação com o coletivo, com as comunidades) (VITORINO; PIANTOLA, 2011). Nessa perspectiva, algumas dessas dimensões podem ser observadas em atividades desenvolvidas pela Biblioteca Pública Dr. Isaías Paim.

Segundo dados obtidos na entrevista on-line, a biblioteca desenvolve uma série de projetos, alguns promovidos entre pessoas da comunidade em geral, outros para públicos específicos, como é o caso do projeto "Semana Pedagógica", voltados à formação continuada de professores, o que caracteriza uma conexão com a dimensão técnica da competência em informação, posto que envolve temáticas direcionadas ao aprimoramento das atividades profissionais. Para os servidores colaboradores da biblioteca, a dimensão técnica, também conectada à competência em informação faz-se presente porque aos mesmos são oferecidos treinamentos e capacitações para que possam atender programas específicos para deficientes visuais e, também, de Libras, contemplando pessoas com deficiência auditiva. De acordo com Oliveira (2014), a dimensão técnica da competência em informação, condiz com a percepção em que habilidades são necessárias no processo de busca da informação, a fim de resolver um problema ou uma necessidade informacional.

A dimensão estética é identificada em oficinas como teatro de fantoche, pois abarca a criatividade sensível das pessoas. Para as crianças, no mês de outubro, são privilegiadas atividades envolvendo leitura, cinema e atividades lúdicas diversas. Atividades desta natureza podem proporcionar a capacidade de compreender, relacionar e ressignificar a informação. Para Orelo e Vitorino (2012), a dimensão estética contribui para a construção do conhecimento pela 
sensibilidade e com as percepções de mundo. Como está estritamente ligada à ética, tem influência no exercício da cidadania com responsabilidade, e na formação para uma visão crítica.

Vislumbra-se uma conexão com a dimensão ética da competência em informação quando se declara que o espaço é público, atendendo pessoas em geral, sejam "moradores de rua", estudantes ou pesquisadores. Compreende-se que a organização biblioteca pública está inclusive atendendo a missão que the foi atribuída, ou ao menos parte dela. A dimensão ética está alicerçada no princípio da solidariedade e do respeito, visando um bem coletivo (VITORINO; PIANTOLA, 2011), estando conectada à seguinte afirmação da bibliotecária enquanto sujeito da pesquisa: "[...] para qualquer pessoa que precisar desse espaço buscamos prestar um atendimento de qualidade".

Há cinco anos a biblioteca pública pesquisada tem conseguido manter recursos financeiros para o desenvolvimento de alguns projetos, o que anteriormente não acontecia. Tal realidade, certamente, tem sido fruto do interesse das pessoas pelos projetos oferecidos, entretanto, exige uma articulação política e, assim, vislumbramos a dimensão política da competência em informação, que entre algumas de suas características engloba a cidadania. Toda a ação da coordenadoria da biblioteca pública está relacionada com a construção coletiva da sociedade, na promoção da relação do homem com esta sociedade/comunidade, sendo vários os agentes públicos envolvidos em tais projetos. Para Lucca (2015), a dimensão política da competência em informação, tem a sua compreensão no entendimento do homem enquanto ser social, ou seja, membro de uma comunidade/sociedade. Um homem pleno da sua cidadania, de acordo com esta dimensão, significa a igualdade nas oportunidades de acesso à informação.

Apesar de terem sido identificados alguns elementos relacionados às dimensões técnica, estética, ética e política da competência em informação, não foram constatados, em uma investigação preliminar, indícios de um programa ou projeto de competência em informação. Tal abordagem foi associada à divulgação de informações sobre o que acontece na biblioteca, ou à difusão de informações sobre suas atividades, conforme narrativa do sujeito entrevistado: 
"Nós temos um espaço no site do Governo do Estado de Mato Grosso do Sul. É um especo [sic] reservado para divulgar todas as informações do que acontece na biblioteca e também para a inscrição da população em nossos projetos".

Na biblioteca pública em questão, o perfil dos usuários é baseado no controle de empréstimos e no site que acessam: "Geralmente pelo controle de empréstimos dos livros (o público que mais utiliza são estudantes) ou pelo site que eles acessam (que neste caso a maioria que utilizam os computadores são moradores de rua)". Assim, surgem indagações: o que fazem com essas informações? Compram livros a partir dos assuntos mais pesquisados? Promovem oficinas e projetos baseados nas necessidades desses perfis? Quais são essas necessidades? Por que os "moradores de rua" acessam determinados sites? Que sites são esses? A partir de contato prévio com a coordenação da biblioteca, pode-se observar que não existem projetos ou programas voltados às necessidades informacionais das pessoas em situação de rua, em especial. Fazse necessário, portanto, investigação mais aprofundada para obter a resposta a algumas dessas questões.

\section{A COMPETÊNCIA EM INFORMAÇÃO COMO UM PROGRAMA: PERMANECER PARA SER}

Mesmo não tendo sido identificado um programa ou projeto de competência em informação na Biblioteca Pública Estadual Dr. Isaías Paim, compreende-se que o ambiente organizacional, cujo conhecimento prévio foi proporcionado por meio desta pesquisa inicial, é favorável à sistematização de atividades que a promovam.

A biblioteca de fato tem sido bastante atuante no sentido de oferecer projetos, alguns de iniciativa própria, e muitos em parceria com outras instituições, incluindo-se universidades ou professores de universidades, que a procuram para desenvolver ali os seus projetos, envolvendo públicos específicos como de unidades de internação prisional de jovens infratores, acadêmicos, entre outros, conforme a especificidade do projeto. Segundo a coordenação, o espaço está disponível, a mídia para divulgação em meios como televisão e 
rádios locais também são acessíveis, passando a abrir, inclusive, aos sábados à tarde, nos últimos anos, para acolhimento dessas propostas da comunidade.

Assim, percebe-se uma abertura do ambiente organizacional interno, com disposição para trocar e se relacionar com o ambiente externo. Deixa-se claro, entretanto, que esta é a percepção de um sujeito, no caso a responsável pela coordenação da biblioteca. Não se obteve resposta, até a finalização deste artigo, quanto ao questionamento das atribuições e atividades de cada um dos quatorze colaboradores/funcionários, incluindo-se dois estagiários. E, ao que consta em um primeiro momento, a própria coordenação encarrega-se de abrir a biblioteca aos sábados para receber os usuários inscritos em determinadas oficinas, palestras, debates sobre filmes projetados, e outros.

Em virtude de as pessoas em situação de rua serem frequentadores assíduos da biblioteca, tendo sido, inclusive, tal fato noticiado em jornais locais, e confirmado pela coordenadoria da biblioteca, pretende-se fazer um levantamento das necessidades informacionais dessas pessoas, desenvolver $\mathrm{e}$ validar um programa que contemple essa competência, voltado à população nesta condição, na Cidade de Campo Grande, Mato Grosso do Sul.

Como um programa que precisa ser desenvolvido, sendo entendido como um processo, a competência em informação precisa ter constância, necessitando aos olhos de quem está à frente de organizações como uma biblioteca pública, ser compreendida a relevância de ser um programa constante, ou em conformidade com a Declaração de Alexandria, que compreende a competência em informação no cerne do aprendizado ao longo da vida (GARNER, 2006). Salienta-se que, como tal processo leva em conta a educação contínua ou aprendizagem ao longo da vida, está incorporada ao conceito da competência em informação.

Se pessoas em situação de rua têm procurado a biblioteca pública, a biblioteca pode melhor acolhê-los, no sentido de saber o que de fato eles ali buscam ou quais são essas necessidades informacionais. Investigando-se, descobriu-se que vários são os gatilhos e situações para que uma pessoa passe a viver na rua, mas na Pesquisa Nacional sobre a População em Situação de Rua, o desemprego é o segundo mais citado (29,8\%), estando atrás de 
problemas como alcoolismo/ou drogas (35,5\%) (BRASIL, 2009).

Entende-se que um programa de competência em informação a ser desenvolvido com esse grupo de pessoas em espaço de uma biblioteca pública, cujo histórico está articulado com a presença de parcela delas, possa contribuir para que aumentem as suas perspectivas de uma realidade melhor. Afinal, conforme explica Belluzzo (2018, p. 29) a "Colnfo também é reconhecida como uma competência essencial para o desempenho no trabalho [...] Aqueles que não tiverem boas habilidades de informação serão marginalizados na vida privada e pública, incluindo problemas de empregabilidade". Contudo, ressaltase que o programa a ser proposto, deve abarcar no mínimo, as quatro dimensões de Vitorino e Piantola (2011), posto que conforme já mencionado, todas as dimensões devem complementar-se, pois assim tem-se uma visão holística das pessoas envolvidas, tanto do ambiente interno, quanto do ambiente externo da organização, o que, certamente, propiciará que a biblioteca pública desenvolva papel fundamental para a participação social, articulação cidadã, além de se configurar como um equipamento cultural e educacional essencial na sociedade contemporânea.

\section{CONSIDERAÇÕES FINAIS}

Morin (2002, p. 225) em seu livro "Método 3: o conhecimento do conhecimento" faz a seguinte afirmação: "[...] conhece-se para viver; depois, quando o conhecimento se emancipa, vive-se para conhecer". Nesse sentido, e levando-se em conta o que neste estudo foi exposto e apresentado, acerca da competência em informação, suas dimensões, a realidade constituída a partir de uma organização que tem como missão a sistematização de programas de educação, informação, cultura e lazer, acredita-se que um programa de competência em informação para a Biblioteca Pública Estadual Dr. Isaías Paim voltará o olhar para as pessoas em situação de rua, dando-lhes chance de quem sabe, resgatar a própria dignidade, uma vez que o acesso e uso da informação de modo inteligente são fundamentais à participação dos indivíduos nos processos decisórios, sendo elemento fundamental para que possam fazer suas 
escolhas e opções. Busca-se não só a emancipação do conhecimento, mas, sobretudo a emancipação dessas pessoas por meio do conhecimento. Mas que conhecimento? O conhecimento que pode advir a partir de suas necessidades informacionais, o conhecimento que está por ser emancipado, o conhecimento que pode trazer-Ihes a vida, e, a partir daí, viverem para conhecer, a si próprios, e o mundo em que vivem.

\section{REFERÊNCIAS}

ALMEIDA, J. L. S.; FREIRE, G. H. A. A biblioteca como organização aprendente na perspectiva da competência em informação. In: ENCONTRO NACIONAL DE PESQUISA EM CIÉNCIA DA INFORMAÇÃO - ENANCIB, 19., 2018, Londrina, PR. Anais Eletrônico... Londrina: UEL. Disponível em: https://brapci.inf.br/index.php/res/v/102245. Acesso em: 06 jul. 2019.

ALMEIDA JÚNIOR, O. F. Mediação da informação: um conceito atualizado. In: BORTOLIN, S.; SANTOS NETO, J. A.; SILVA, R. J. (Orgs.). Mediação oral da informação e da leitura. Londrina: ABECIN Editora, 2015. 278 p.

ARAGÃO, A. Prevenção de riscos na União Europeia: o dever de tomar em consideração a vulnerabilidade social para uma proteção civil eficaz e justa. Revista Crítica de Ciências Sociais, Coimbra, n. 93. Quadrimestral, 2011. Disponível em: https://journals.openedition.org/rccs/174. Acesso em: 18 fev. 2020.

ASSOCIATION OF COLLEGE AND RESEARCH LIBRARIES (ACRL). Framework for Information Literacy for Higher Education. Chicago: ALA, 2015. Disponível em:

http://www.ala.org/acrl/sites/ala.org.acrl/files/content/issues/inf olit/Framework_ILHE.pdf. Acesso em: 17 set. 2020.

BELLUZZO, R. C. B. A competência em informação no Brasil: cenários e espectros. São Paulo: ABECIN Editora, 2018. Disponível em:

http://abecin.org.br/data/documents/E-Book_Belluzzo.pdf. Acesso em: 14 jul. 2019. (livro digital)

BELLUZZO, R. C. B.; SANTOS, C. A.; ALMEIDA JUNIOR, O. F. A Competência em informação e sua avaliação sob a ótica da mediação da informação: reflexões e aproximações teóricas. Informação \& Informação, Londrina (PR), v. 19, n. 2, p. 60-77, maio/ago. 2014. Disponível em: http://www.uel.br/revistas/uel/index.php/informacao/article/view/19995/pdf_21. Acesso em: 13 jul. 2019. 
BRASIL. Ministério do Desenvolvimento Social e Combate à fome. Rua: aprendendo a contar: Pesquisa Nacional sobre a População em Situação de Rua. Brasília, DF: MDS, 2009. 240 p. Disponível em:

https://www.mds.gov.br/webarquivos/publicacao/assistencia_social/Livros/Rua_ aprendendo_a_contar.pdf. Acesso em: 14 jul. 2019.

BURKE, P. Uma história social do conhecimento: de Gutenberg a Diderot. Rio de Janeiro: Zahar, 2003. 241 p.

BUSSO, G. Vulnerabilidad social: nociones e implicancias de políticas para latinoamerica a inicios del siglo XXI. In: SEMINÁRIO INTERNACIONAL LAS DIFERENTES EXPRESIONES DE LA VULNERABILIDAD SOCIAL EN AMÉRICA LATINA Y EL CARIBE, 2001, Santiago do Chile. Disponível em: http://www.derechoshumanos.unlp.edu.ar/assets/files/documentos/vulnerabilida d-social-nociones-e-implicancias-de-politicas-para-latinoamerica-a-inicios-delsiglo-xxi.pdf. Acesso em: 18 fev. 2020.

CARVALHO, I. C. L. A socialização do conhecimento no espaço das bibliotecas universitárias. Niterói: Intertexto, 2004. 185 p.

CAVALCANTE, L. F. B., VALENTIM, M. L. P. Informação e conhecimento no contexto de ambientes organizacionais. In: VALENTIM, M. L. P. (Org.). Gestão, mediação e uso da informação. São Paulo: Cultura Acadêmica, 2010. 234 p.

FLICK, U. Introdução à metodologia de pesquisa: uma guia para iniciantes. Porto Alegre: Penso, 2013. 256 p.

FONSECA, E. N. Introdução à Biblioteconomia. 2. ed. Brasília: Briquet de Lemos, 2007. $152 \mathrm{p}$.

GASQUE, K. C. G. Comportamento, letramento informacional e pesquisas sobre o cérebro: aplicações na aprendizagem. Informação em Pauta, Fortaleza, CE, v. 2, número especial, out. 2017. Disponível em: http://www.periodicos.ufc.br/informacaoempauta/article/view/20649/31062. Acesso em: 17 set. 2020.

GARNER, S. D. High-level Colloquium on Information Literacy and Lifelong Learning. Alexandria: UNESCO/NFIL/IFLA, 2006. Disponível em: https://www.ifla.org/files/assets/information-literacy/publications/high-levelcolloquium-2005.pdf. Acesso em: 13 jul. 2019.

ILHARCO, F. Filosofia da informação. Lisboa: Universidade Católica Editora, 2003. $202 \mathrm{p}$.

INTERNATIONAL FEDERATION OF LIBRARY ASSOCIATIONS AND INSTITUTIONS (IFLA). Manifesto da IFLA/UNESCO sobre bibliotecas públicas 1994. Paris: UNESCO, 1994. Disponível em: 
https://www.ifla.org/files/assets/public-libraries/publications/PL-manifesto/plmanifesto-pt.pdf. Acesso em: 12 jul. 2019.

JUSTO, J. S. Andarilhos e trecheiros: errância e nomadismo na contemporaneidade. Maringá: EDUEM, 2011. 218 p.

LUCCA, D. M. A dimensão política da competência informacional: um estudo a partir das necessidades informacionais de idosos. 2015. $287 \mathrm{f}$. Dissertação (Mestrado em Ciência da Informação) - Universidade Federal de Santa Catarina, Florianópolis, 2015.

MANIFESTO de Florianópolis sobre a competência em informação e as populações vulneráveis e minorias. In: SEMINÁRIO "COMPETÊNCIA EM INFORMAÇÃO: CENÁRIOS E TENDÊNCIAS", 2., 2013, Florianópolis. Disponível em: http://febab.org.br/manifesto_florianopolis_portugues.pdf. Acesso em: 13 jul. 2019.

MANZINI, E. J. Entrevista semi-estruturada: análise de objetivos e de roteiros. In: SEMINÁRIO INTERNACIONAL SOBRE PESQUISA E ESTUDOS QUALITATIVOS, 2., 2004, Bauru. A pesquisa qualitativa em debate. Anais... Bauru: USC, 2004. CD-ROOM. ISBN: 85-98623-01-6. 10p.

MARCONI, M. A.; LAKATOS, E. M. Técnicas de pesquisa: planejamento e execução de pesquisas, amostragens e técnicas de pesquisa, elaboração, análise e interpretação de dados. 7. ed. São Paulo: Atlas, 2016. xiii, 277 p.

MATTELART, A. História da sociedade da informação. 2. ed. São Paulo: Loyola, $2006.197 \mathrm{p}$.

MORIN, E. O método 3: o conhecimento do conhecimento. 2. ed. Porto Alegre: Sulina, 2002. 288p.

OLIVEIRA, A. P. A dimensão técnica da competência informacional: estudos com bibliotecários de referência das bibliotecas universitárias da grande Florianópolis, SC. 2014. 205 f. Dissertação (Mestrado em Ciência da Informação) - Universidade Federal de Santa Catarina, Florianópolis, 2014.

ORELO, E. R. M.; VITORINO, E. V. Competência informacional: um olhar para a dimensão estética. Perspectiva em Ciência da Informação, Belo Horizonte, v.17, n.4, p.41-56, out./dez. 2012. Disponível em: www.scielo.br/pdf/pci/v17n4/04.pdf. Acesso em: 14 jul. 2019.

SANTOS NETO, J. A.; ALMEIDA JÚNIOR, O. F. A competência em informação e o bibliotecário mediador da informação na biblioteca universitária. In: BORTOLIN, S.; SANTOS NETO, J. A.; SILVA, R. J. (Orgs.). Mediação oral da informação e da leitura. Londrina: ABECIN Editora, 2015. 278 p.

VALENTIM, M. L. Tendências e perspectivas profissionais e as competências 
essenciais para a formação e a atuação do bibliotecário. Revista Eletrônica da ABDF, Brasília, v. 3, n. 2, p. 46-63, jul./dez. 2019. Disponível em: http://revista.abdf.org.br/abdf/article/view/23/54. Acesso em: 15 fev. 2020.

VITORINO, E. V. A competência em informação e a vulnerabilidade: construindo sentidos à temática da "vulnerabilidade em informação". Ciência da Informação, Brasília, v. 47 n. 2, p. 71-85, maio/ago. 2018. Disponível em: http://revista.ibict.br/ciinf/article/view/4187/3794. Acesso em: 13 jul. 2019.

VITORINO, E. V.; PIANTOLA, D. Dimensões da Competência informacional. Ciência da Informação, Brasília, v. 40, n. 1, p. 99-110, jan./abr. 2011. Disponível em: http://www.scielo.br/pdf/ci/v40n1/a08v40n1.pdf. Acesso em: 13 jul. 2019.

\title{
THE INFLUENCE OF THE ORGANIZATIONAL ENVIRONMENT IN THE DEVELOPMENT OF AN INFORMATION LITERACY PROGRAM: THE CASE OF A PUBLIC LIBRARY
}

\begin{abstract}
Introduction: It presents the public library as a mediation space, whose organizational environment has an influence on the construction of the user's knowledge, and therefore on the development of an information literacy program. Objective: To reflect on the influence of the organizational environment for the development of an information literacy program. Methodology: This is a qualitative study, based on a literature review carried out on the CAPES Journals Portal involving the themes 'information', 'knowledge', 'sociology of information and knowledge', 'information literacy', 'public library' and 'library as an organization'. It is also a field research, using the semi structured interview technique. Results: The semi structured interview conducted with the head of the State Public Library Dr. Isaías Paim, in Campo Grande City, Mato Grosso do Sul State, shows that activities developed in this space, present elements related to dimensions of information literacy, however they do not present a program or project aimed at this end. Conclusions: It is understood that the organizational environment of public libraries is influenced by internal and external conditions that interfere in the conditions of information access, especially for people in conditions of social vulnerability, such as people on the street who frequent these organizations.
\end{abstract}

Keywords: Public Library. Organizational environment. Information Literacy. Social Vulnerability.

\section{LA INFLUENCIA DEL AMBIENTE ORGANIZACIONAL EN EL DESARROLLO DE UN PROGRAMA DE ALFABETIZACIÓN INFORMACIONAL: EL CASO DE UNA BIBLIOTECA PÚBLICA}




\section{RESUMEN}

Introducción: Presenta la biblioteca pública como un espacio de mediación, cuyo entorno organizacional influye en la construcción del conocimiento del usuario y, por lo tanto, en el desarrollo de un programa de alfabetización informacional. Objetivo: reflexionar sobre la influencia del entorno organizacional para el desarrollo de un programa de alfabetización informacional. Metodología: Es un estudio cualitativo, basado en una revisión de literatura realizada en el Portal de Periódicos de la CAPES que involucra los temas 'información', 'conocimiento', 'sociología de la información y conocimiento', 'alfabetización informacional', 'biblioteca pública' y 'biblioteca como organización'. También es una investigación de campo, utilizando la técnica de entrevista semiestructurada. Resultados: La entrevista semiestructurada realizada con el jefe de la Biblioteca Pública del Estado, Dr. Isaías Paim, en la ciudad de Campo Grande, estado de Mato Grosso do Sul, muestra que las actividades desarrolladas en este espacio presentan elementos relacionados con las dimensiones de la alfabetización informacional, sin embargo, presentar un programa o proyecto dirigido a este propósito. Conclusiones: Se entiende que el entorno organizacional de las bibliotecas públicas está influenciado por condiciones internas y externas que interfieren en las condiciones de acceso a la información, especialmente para las personas en condiciones de vulnerabilidad social, como las personas en la calle que frecuentan estas organizaciones.

Palabras-Clave: Biblioteca Pública. Entorno Organizacional. Alfabetización Informacional. Vulnerabilidad Social.

Recebido em: 29.03.2020

Aceito em: 26.10.2020 